\title{
PRESENTE Y FUTURO \\ DE LA POLITICA FAMILIAR \\ EN ESPAÑA
}

\section{Gerardo Meil Landwerlin}

Universidad Autónoma de Madrid

Antes de abordar cualquier discusión sobre la política familiar es frecuente discutir el propio concepto de política familiar, pues todas las políticas públicas, y en especial las políticas económica y social, pueden ser reinterpretadas en términos de política familiar al beneficiar de manera directa o indirecta a las familias. Dada la ausencia de espacio disponible para acometer tal discusión, nos limitaremos a señalar, antes de proceder a la discusión del presente y futuro de la política familiar española, lo que entendemos en este contexto por política familiar.

Por política familiar entendemos el conjunto de medidas o instrumentos de política pública más o menos articulados para reconocer las funciones sociales que cumplen las familias ${ }^{1}$. La política familiar presupone así un punto de vista familiar, en el sentido del establecimiento de unos objetivos y la presencia de unos valores explicitados en relación a la familia ${ }^{2}$, que se utilizan como legi-

1 Para más detalles, véanse, entre otros, S. Kamerman y A. Kahn (eds.), Family Policy. Government and Families in Fourteen Countries, New York; G. MeIL, "Política familiar: contenido y significado", en Revista Internacional de Sociología, tercera época, 1, 1992, pp. 173 y ss.; S. Zimmerman (1988), Understanding Family Policy. Theoretical Approaches, Sage, Newsbury.

${ }^{2}$ Estos valores no necesariamente deben circunscribirse a la promoción de un único modelo de familia. Por el contrario, uno de los valores centrales de las políticas familiares actuales es precisamente el respeto a la pluralización de las formas de vida familiar. En este sentido, los valores de la PF pueden ser, por ejemplo, la neutralidad frente al tipo de vínculo matrimonial, la facili- 
timación para la intervención en la dinámica familiar. Según sea el grado de articulación de valores, objetivos y medidas políticas, la política familiar estará más o menos desarrollada, pudiéndose hablar entonces de política familiar explícita o implícita, tal como proponen Kamermann y Kahn (1978).

Dentro de la política familiar podemos distinguir tres grandes dimensiones de intervención en la dinámica familiar, a saber: en un primer plano, por un lado, la intervención legal y, por otro, la intervención económica o compensación pública de cargas familiares, destinada a incrementar los recursos económicos disponibles de las familias en función de las cargas familiares a las que tienen que hacer frente. Ambos tipos de intervención son elaborados desde el poder central. En tercer lugar se encuentra la intervención mediante servicios sociales en el plano descentralizado (Regiones y Administración Local), que está destinada a mejorar los recursos o capacidades de las familias con el objetivo de facilitar o posibilitar el cumplimiento de las funciones familiares.

Hechas estas precisiones y desde esta perspectiva, procedemos a analizar la política familiar española en la actualidad.

\section{GRANDES LINEAS DE DESARROLLO DE LA POLITICA FAMILIAR ESPAÑOLA}

Durante el franquismo, la política familiar ocupó un lugar privilegiado dentro del sistema de protección social puesto en marcha por el régimen. En efecto, en la construcción del incipiente Estado de bienestar por parte del nuevo poder surgido a partir de la Guerra Civil, la familia ocupó un lugar central. Este lugar central de la familia no derivaba sólo de la articulación de la protección social a través de la protección del asalariado cabeza de familia (posteriormente también de los trabajadores autónomos) y, a través suyo, a toda la familia (extensa primero, nuclear después) en virtud de los derechos derivados, como es propio de todo modelo contributivo y a diferencia de los modelos universalistas basados en los derechos individuales de los ciudadanos. En un sentido mucho más radical, lo que se llegó a implantar con la sucesiva introducción de distintas prestaciones familiares fue una determinada concepción del salario familiar, en virtud de la cual el salario no sólo dependía de la cualificación profesional y la productividad, sino del número de cargas familiares. Estas prestaciones familiares tenían como objeto no garantizar la falta de ingresos del cabeza de familia, sino la compensación pública de las cargas familiares o, expresado en otros términos, el reparto de parte de los costes de crianza de los hijos entre un colectivo más amplio. Y esta compensación pública de

tación de la reincorporación laboral de las mujeres que han interrumpido sus biografías laborales por causas familiares, la facilitación a los progenitores de la compatibilidad entre trabajo extradoméstico y la asunción de cargas familiares, la garantía de un mínimo existencial a todos los menores, la garantía de un entorno familiar normalizado a éstos, etc. 
las cargas familiares podía llegar a representar, según los casos, una parte muy importante de la renta disponible de las familias. Con la modernización económica y social de la década de los sesenta, esta centralidad de la protección social de la familia perdió importancia, sobre todo por el crecimiento del nivel de vida, si bien continuó ocupando un papel no despreciable en la renta disponible de las familias.

En contra de lo que habitualmente suele afirmarse, la principal motivación de la política familiar franquista, tanto de la etapa autárquica como en la etapa desarrollista, era fundamentalmente compensatoria (en el sentido en el que habitualmente se entiende en el marco de la política social) antes que demográfica $^{3}$. Con la implantación del salario familiar y otras prestaciones familiares lo que se pretendió en un principio era, ante todo, elevar el nivel de renta de las familias de asalariados con mayor número de cargas familiares, que eran las que en mayor riesgo de pobreza se encontraban. Con ello se esperaba garantizar en un principio un mínimo vital a todas las familias y resolver la supuesta crisis de la familia generada por el liberalismo económico y político, si bien finalmente sirvió para paliar los efectos de la draconiana política de rentas practicada por las nuevas autoridades. En este sentido la política familiar se convirtió, de hecho, en una política de lucha contra la pobreza a gran escala. Como consecuencia de la mejora de la renta disponible de las familias se esperaba que se produjera una recuperación de la natalidad. Junto a esta política compensatoria-demográfica, la política familiar franquista persiguió activamente, a través tanto de la intervención jurídica como económica y propagandística, la implantación, más que promoción, del modelo de vida familiar habitualmente calificado como tradicional, esto es, con una segregación de roles y de la autoridad según sexo y edad.

Esta concepción de la protección social de la familia, que presentaba contradicciones y disfuncionalidades que hemos analizado en otro lugar ${ }^{4}$, quedó deslegitimada con los profundos cambios que acompañaron a la transición política. Junto a esta deslegitimación ideológica se produjo, además, un desplazamiento en las prioridades de la política social derivadas de los nuevos problemas sociales planteados por la crisis económica y el envejecimiento de la población. Durante la transición política, la protección social de las cargas familiares desapareció de la arena política, para no volver a aparecer, como veremos, hasta muy recientemente. En el Parlamento apenas se registró sensibilidad alguna hacia esta dimensión de la política social. Hasta la discusión del proyecto de Ley de pensiones no contributivas, en septiembre de 1990, se contabilizan únicamente: una proposición de ley sobre protección a la familia (2010-1984), que fue retirada sin llegar a discutirse — se presentó nuevamente un

3 Para más detalles, cf. G. MeIL (1994), «L'évolution de la politique familiale en Espagne: Du salaire familiale à la lutte contre la pauvreté», en Population, 4-5, y G. MeIL (1995), "La política familiar franquista», en Revista Internacional de Sociología, n. ${ }^{\circ} 11$ (pp. 47-48).

${ }^{4}$ Cf. MeIl (1995), op. cit. 
año más tarde (1-10-1985) para correr igual suerte-; cinco proposiciones no de ley que o bien fueron aprobadas pero ignoradas (1978; 5-5-1988), caducó sin discutirse (4-1982; 26-10-1989) o se desestimó (4-3-1988); once preguntas con respuesta escrita que no tuvieron efecto alguno (cinco en 1983, dos en 1987 , tres en 1988 y una en 1989); tres con respuesta oral que corrieron igual suerte (una en 1988 y dos en 1989). Las asociaciones familiares tampoco tuvieron importancia ni fuerza alguna para promover una nueva política familiar acorde con la pluralización de las formas de vida familiar, y en la agenda política del resto de agentes sociales tampoco tenía cabida.

Como consecuencia de esta salida de la dimensión económica de la política familiar de la arena política, las prestaciones directas de la Seguridad Social se volvieron ridículas y la reforma y modificaciones sucesivas de la imposición directa sobre la renta de las personas físicas se hicieron básicamente al margen de consideraciones familiares, hasta el punto incluso de declararse inconstitucional en 1989 por discriminar negativamente a los matrimonios con dos perceptores de rentas 5 . Esta pérdida de relevancia de la compensación pública de las cargas familiares ha supuesto que el protagonismo de la política familiar haya sido asumido por otras dimensiones de la intervención pública en la dinámica familiar, cuando en otros países con una política familiar explícita y desarrollada aquélla es la dimensión que, en el análisis científico, más atención concita.

Así, la política familiar española durante este período se ha plasmado fundamentalmente, por un lado, en la intervención legal de la familia. Las medidas más importantes tomadas en esta dimensión, y que constituyen el marco legal que regula actualmente las relaciones familiares, son, lógicamente, la reforma de la legislación familiar heredada del franquismo, acometida en 1981 con la reforma del Código civil; la aprobación de una Ley de divorcio, así como de una Ley reguladora del aborto $(1983)^{6}$. Pero la dimensión legal ha sido también importante, al menos en otros dos puntos. Por un lado, en la ampliación del reconocimiento de derechos propios a los menores, iniciándose así un camino hacia el establecimiento de una política específica destinada a la infancia ${ }^{7}$. En este sentido hay que señalar, primero, la modificación en 1987 de la Ley de adopción para introducir un mayor respeto a los derechos de los menores, al tiempo que introduce nuevas figuras intermedias entre la retirada de la custodia y la inserción familiar definitiva, ya utilizadas con éxito en algunos países europeos (acogimiento familiar), y que ha sido actualizada y ampliada en 1995 con la nueva Ley de protección jurídica del menor y la modificación parcial del Código civil. Por otro lado, la dimensión legal volverá a adqui-

5 Para más detalles, véase Julio Iglesias de Ussel, Lluís Flaquer y Gerardo MeIL, «La familia», en FOESSA, V Informe sociológico sobre la realidad social en España, Madrid, 1994, pp.

${ }^{6}$ Cf. J. Iglesias de Ussel (1991), «La familia en la transición política», en J. Vidal Beneyto (ed.), España a debate. II. La sociedad, Tecnos, Madrid.

Cf. Ministerio de Asuntos Sociales (1991), Investigación y políticas de infancia en Europa en los años 90, Madrid. 
rir también importancia si se plasma en la próxima reforma del Código penal, como parece va a ser el caso, penas más severas contra aquellos progenitores (padres, generalmente) que incumplan su obligación de pago de la pensión de alimentos, solución que ha comenzado a implantarse ya en la práctica judicial.

Por otro lado, la otra dimensión de la política familiar que ha adquirido mayor relevancia ante la desaparición de la compensación pública de cargas familiares de la arena política ha sido la política de servicios sociales. Los servicios sociales han ido adquiriendo cada vez una mayor importancia a medida que ha ido madurando el Estado de bienestar español, al igual que ha sucedido con el resto de países con un Estado de bienestar desarrollado. Comoquiera que los servicios sociales están orientados mayormente a proporcionar recursos en situaciones familiares problemáticas, éstos han pasado a representar la dimensión más palpable de la política familiar. A esta circunstancia hay que añadir, además, la tendencia actual en el ámbito de los servicios sociales a revalorizar el papel de la familia en la resolución de los problemas sociales. Así, frente a la institucionalización se promueve activamente la recomposición de la funcionalidad del núcleo familiar o de la solidaridad familiar, y para ello se promueve activamente la creación de servicios de apoyo a las familias en crisis, en riesgo de estarlo o en dificultad social de distinto tipo (servicios de respiro, formación, ayudas específicas, el acogimiento familiar, etc.), a fin de que las familias puedan, efectivamente, asumir cargas familiares sin menoscabo de los derechos y del bienestar individuales.

La atención concitada por estas dos dimensiones al referirse los distintos agentes sociales a la política familiar española (junto a las propias distorsiones ideológicas) ha hecho que ésta haya perdido entidad propia en mayor medida aún de lo que es habitual en la discusión científica. No existe así, ni entre los agentes políticos que definen las políticas públicas en la arena política ni entre muchos investigadores sociales, ni debate ni consenso sobre el significado y el alcance de una política familiar.

La evolución reciente de la política familiar española puede caracterizarse, por tanto, mediante tres grandes rasgos, a saber: privatización, asistencialización y fragmentación.

La pérdida de importancia de las prestaciones directas de la Seguridad Social destinadas a compensar cargas familiares, de un lado, y la escasa sensibilidad de la imposición sobre la renta a las cargas familiares, de otro, hacen, como se verá en el próximo epígrafe, que la renta neta disponible de las familias apenas sea sensible a las cargas familiares a las que tienen que hacer frente. En este sentido, por tanto, los costes derivados de la asunción de cargas familiares no se reconocen socialmente y constituyen opciones individuales de gasto. Aunque sin una declaración expresa en tal sentido, la política familiar española actual ha hecho suyos los planteamientos de la economía de la familia encabezada por Gary Becker: las opciones en favor de la maternidad son consecuencia de una evaluación por parte de los padres que se salda con una ganancia de utilidad esperada frente a los costes que ello supone. Dado que la 
utilidad derivada de la presencia de los hijos es, por tanto, positiva, no hay necesidad de compensación pública de los costes derivados de tal opción. Dado que los hijos no solamente constituyen un bien individualmente consumible, esto es, que proporciona utilidades individuales, sino que también tienen una rentabilidad social (producción de ciudadanos socializados), puede decirse que la política familiar española actual ha privatizado buena parte de los costes de crianza de los hijos ${ }^{8}$, aunque los beneficios sigan siendo por naturaleza socializados.

La limitación de las prestaciones familiares directas de la Seguridad Social a las familias con menores ingresos y/o con hijos minusválidos mayores a partir de la Ley 26/1990, de pensiones no contributivas, ha supuesto la asistencialización de la política familiar, como tendrá ocasión de comprobarse en el próximo epígrafe, por más que dicha medida pueda ser interpretada como la universalización de la prestación indirecta concedida a través de la deducción de la cuota del IRPF a aquellas familias que se encuentran por debajo del umbral de la imposición. Este rasgo fundamental se ve reforzado, además, por un lado, por el citado protagonismo dentro de la política familiar de los servicios sociales destinados a las familias en situaciones de necesidad. Pero este rasgo también puede observarse, por otro lado, en la mejora de las condiciones de acceso a otras prestaciones sociales cuando hay presencia de cargas familiares (pensiones mínimas y prestaciones sociales por desempleo).

Con la referencia a la fragmentación de la política familiar queremos aludir al hecho, por un lado, de la desaparición de una perspectiva integral de la política familiar, de un punto de vista familiar, y a la emergencia, por otro lado, de políticas específicas destinadas a la mujer y a la infancia. Esta diferenciación de la política pública, siendo funcional en determinados aspectos ${ }^{9}$, ha comportado, sin embargo, una cierta falta de sensibilidad hacia otras situaciones en las que se producen conflictos de rol. Este es el caso de la insuficiente sensibilidad hacia el problema de la compatibilización de maternidad y trabajo extradoméstico, que en algunos Estados de bienestar ha pasado a constituir uno de los ejes fundamentales de la política familiar. Es tradicional en la mayor parte de los Estados de bienestar las denuncias de falta de servicios de apoyo a las madres trabajadoras con hijos pequeños ${ }^{10}$ que quieren compatibilizar ambas tareas. En

${ }^{8}$ Salvo los nada despreciables costes de educación y sanidad, que se han socializado. Esta socialización, no obstante, no responde a criterios de PF, sino de integración social y desarrollo económico.

${ }^{9}$ Así, la política de promoción de la igualdad entre hombres y mujeres, independientemente del balance concreto que pueda sacarse sobre los objetivos concretos fijados, representa un importante avance en favor de la disminución de las desigualdades por razón de sexo, entre otras cosas porque ha logrado crear una sensibilidad social y política en torno a un valor que en la sociedad actual de los países desarrollados es «evidente», pero que no lo era hace tan sólo unos cuantos años. Respecto a la política sobre la infancia, también se ha producido un cambio de sensibilidad hacia el reconocimiento de derechos específicos al menor, que redunda en una mayor protección (jurídica, por lo pronto).

${ }^{10}$ Cf. Peter Moos (1990), Cuidado de los hijos e igualdad de oportunidades. Informe de la Red 
algunos países han optado, en lugar de desarrollar servicios de cuidado y educación infantil (guarderías y escuelas infantiles), por introducir un salario de sustitución temporal hasta que el niño tiene edad «suficiente» (donde ésta se define socialmente) para acceder al servicio educativo ${ }^{11}$. En otros, por el contrario, han tratado de implicar a los propios empresarios para fomentar la facilitación por parte de éstos de servicios de respiro par sus trabajadores con cargas familiares y elevar así la productividad de los empleados ${ }^{12}$. En el caso de España, se han ido tomando medidas fragmentadas y diferidas en el tiempo, en algunos casos incluso en contra de las intenciones iniciales del Gobierno ${ }^{13}$. La situación actual, habiendo mejorado apreciablemente, presenta, sin embargo, lagunas tales como la ausencia de reconocimiento como período efectivamente cotizado, a efectos de determinación de la carrera de aseguramiento, del período de excedencia por maternidad superior al año de reserva de puesto de trabajo.

Esta evolución de la política familiar, que en otro lugar hemos resumido con el término "evaporación», parece que está cambiando. Tanto en el ámbito legislativo como en la arena política se ha despertado cierta sensibilidad hacia esta dimensión de la política social. Así, en 1993 fue aprobado el Plan integral de apoyo a las familias elaborado por la Generalitat de Cataluña, y durante la primera mitad de 1995 existen también planes regionales de apoyo a las familias en fase de elaboración en las Comunidades Autónomas de Galicia y de Castilla y León.

El alcance de estos planes es limitado, particularmente en la dimensión de la compensación pública de cargas familiares. La limitación de competencias de las CC.AA. en la materia, y singularmente en lo que se refiere a la legislación laboral, la legislación sobre Seguridad Social y, sobre todo, en materia fiscal, hace que el alcance de estos planes regionales sea, por definición, limitado. A estas limitaciones hay que añadir, además, la propia ambigüedad de lo que

europea de formas de atención a la infancia, Ministerio de Asuntos Sociales, Centro de Estudios del Menor, Madrid, pp. 224 y ss.

${ }^{11}$ Sobre el particular, cf., para Francia, Ph. STECK (1993), Les prestations familiales, PUF, París, pp. 70 y ss. Para Alemania, en castellano, cf. G. MeIL (1991), «El Estado de bienestar ante el desafío demográfico: problemas de la política familiar alemana en el contexto del envejecimiento de la población", en Revista de Estudios Políticos, 72, pp. 271 y ss.

${ }_{12}$ Sobre las interesantes iniciativas tomadas en este sentido, cf. M. B. Neal, N. J. Chapman, B. Ingersoll-Dayton y A. C. EMlen (1993), Balancing Work and Caregiving for Children, Adults and Elders, Sage P., London.

${ }_{13}$ Como principales medidas hay que señalar las Leyes 3/1989, de 3 de marzo, y 8/1992, de 30 de abril, que amplía la baja por maternidad a dieciséis semanas, incluyendo la posibilidad de disfrute parcial de la misma por parte del padre, y el reconocimiento de hasta tres años de excedencia, pero sin reserva de puesto de trabajo cuando aquélla exceda de un año y con reconocimiento del primer año como cotizado. También hay que señalar el cambio de naturaleza y elevación de la prestación por maternidad hasta el cien por cien de la base reguladora a partir de la Ley 42/1994, de 30 de diciembre. Igualmente hay que destacar algunas medidas tomadas recientemente en el ámbito educativo, tales como la utilización de las instalaciones educativas durante los veranos y la reducción de la edad de inicio del período preescolar hasta los tres años, con la consiguiente obligación de proporcionar una plaza a todo niño cuyos padres lo soliciten. 
debe ser la política familiar y lo que significa un plan de intervención social sobre la familia, lo que lleva a una elevada dosis de indeterminación, en unos casos, o a una elevada vinculación con la política de servicios sociales, en otros.

A pesar de estas limitaciones, a las que hay que añadir las propiamente presupuestarias, la existencia de estos planes supone un hecho importante para el objeto de análisis que discutimos. Esta importancia deriva, en primer término, de la propia aparición de una sensibilidad en este sentido y del intento de articulación de una política explícita en este campo. A ello hay que añadir, además, el propio cambio de óptica y de formación y representación de intereses que ello puede comportar y la generación de medidas que suscite. Por otro lado, la existencia de un plan general de apoyo a la familia en Cataluña tiene importancia por las repercusiones que ello tiene sobre el actual acuerdo de gobierno que existe entre los dos partidos de gobierno (PSOE en el ámbito nacional y $\mathrm{CiU}$ en el ámbito catalán). De hecho, algunas de las medidas de política familiar recientemente tomadas para todo el ámbito nacional (modificación de la Ley de familias numerosas y de la legislación sobre permisos de maternidad) derivan precisamente de las recomendaciones a la Administración central contenidas en el Plan catalán de apoyo a las familias.

En realidad, sin embargo, no puede hablarse de un auténtico cambio, pues la política actual no puede sino calificarse de reticente, como lo demuestra el sistemático retraso en la elaboración del reglamento que desarrolla la nueva Ley de familias numerosas o la ausencia de revalorizaciones desde que se aprobara la Ley, en 1990, tanto de las prestaciones como de los umbrales de ingresos para tener derecho a las prestaciones por hijo a cargo de la Seguridad Social ${ }^{14}$. La arena política en la que se definen las políticas públicas, sin embargo, ha cambiado y, aunque las declaraciones de intenciones del principal partido de la oposición no sirvan para hacer predicciones, sí resultan reveladoras de un cambio de sensibilidad. Entre las muestras de este cambio de sensibilidad se encuentran la elaboración de los citados planes integrales de apoyo a las familias, las declaraciones al hilo del Año Internacional de la Familia y las iniciativas parlamentarias recientemente tomadas en este sentido (modificación al alza de la protección social a las familias numerosas y proposición no de ley para lograr una mayor protección social y económica de la familia).

La disolución de la política familiar en la política de promoción de la igualdad de las mujeres y de la infancia, o la limitación de aquélla fundamentalmente a la dimensión legal y a la intervención básicamente asistencial, fundamentalmente a través de los servicios sociales, no es la única opción posible de desarrollo de la política familiar. Tanto la evolución de las propias situaciones sociales de las familias como la experiencia comparada de los países de nuestro entorno proporcionan argumentos en favor de un mayor apoyo social

${ }_{14} \mathrm{El}$ umbral se ha elevado para 1995 un 8 por 100 (desde 1.000 .000 a 1.080 .540 ptas/año); no así, sin embargo, las prestaciones, que continuaron fijadas en 36.000 ptas. anuales para la prestación básica. 
a las familias que asumen cargas familiares. Antes de analizar los argumentos en favor de una política familiar y las características generales que ésta debería asumir si quiere atenerse a la evolución social, es preciso estudiar la protección social de la familia en España en el marco de la Unión Europea.

\section{LA PROTECCION SOCIAL DE LAS CARGAS FAMILIARES EN ESPAÑA Y EN LA UNION EUROPEA}

Una primera aproximación a la importancia de las prestaciones familiares destinadas a compensar cargas familiares derivadas de la tenencia y cuidado de los hijos la proporcionan las estadísticas de protección social, función familia, elaboradas por Eurostat, y que recogen todo tipo de prestaciones directas (pagos en dinero o en especie, salvo las relacionadas específicamente con la maternidad) pagadas por este concepto. Las divergencias dentro de la Unión Europea en la protección social de las cargas familiares es muy elevada: en 1991, todos los países del sur de la Comunidad (España, Grecia, Portugal e Italia) dedicaban menos de un 1 por 100 del PIB, mientras que en Irlanda, Francia, Bélgica, Luxemburgo y Dinamarca esta proporción se situaba por encima del 2 por 100, hasta alcanzar incluso el 3 por 100 en el caso de Dinamarca (Alemania y los Países Bajos dedicaban una proporción entre un 1,5 y un 2 por 100 del PIB). El país que menores recursos dedicaba a esta función de la protección social era precisamente España, donde en dicho año el monto total del gasto representaba un 0,1 por 100 del PIB (Grecia destinaba un 0,3 por 100 del PIB).

La evolución de estos gastos durante la década de los ochenta ha sido, en el caso español, claramente descendente, hasta el punto incluso de disminuir un 12 por 100 en valores nominales. La evolución en el resto de los países comunitarios no presenta una pauta homogénea, como puede verse en la tabla 1 , pues son tantos los países donde aumenta el gasto como aquellos donde disminuye. Medido en relación al PIB, no obstante, el valor relativo del gasto aumenta sólo en Dinamarca, Irlanda, Luxemburgo y Portugal, países con una intensidad relativa muy elevada.

La representatividad de estos indicadores de compromiso con la compensación pública de las cargas familiares es, sin embargo, limitada. Dos son los principales motivos de esta limitación. Por un lado, porque la evolución de estos indicadores está condicionada por la evolución de la población potencialmente beneficiaria, que, como es sabido, es decreciente como consecuencia de las bajas tasas de natalidad que se registran en casi todos los países de la UE. La segunda limitación deriva del hecho de que las prestaciones directas solamente recogen una dimensión de la compensación públicas de cargas familiares, excluyendo toda consideración del tratamiento fiscal dado a las cargas y situaciones familiares, circunstancia ésta que afecta de modo decisivo a la renta disponible de las familias. 


\section{TABLA 1}

Prestaciones familiares directas a las familias en los paises de la Unión Europea

\begin{tabular}{|c|c|c|c|}
\hline País - Año & $\begin{array}{c}\text { Prest. fam. directas } \\
(\% \text { PIB) }\end{array}$ & $\begin{array}{c}\text { Población menor } \\
\text { de } 20 \text { años (\% total) }\end{array}$ & $\begin{array}{c}\text { Prestación media } \\
\text { (\% PIB por habitante) }\end{array}$ \\
\hline \multicolumn{4}{|l|}{ Bélgica } \\
\hline $1980 \ldots \ldots \ldots \ldots . . .$. & 2,8 & 28,4 & 10,0 \\
\hline 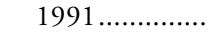 & 2,0 & 24,5 & 8,2 \\
\hline \multicolumn{4}{|l|}{ Dinamarca } \\
\hline $1980 \ldots \ldots \ldots \ldots$ & 2,8 & 28,7 & 9,7 \\
\hline $1991 \ldots \ldots \ldots . . . . .$. & 3,0 & 24,1 & 12,4 \\
\hline \multicolumn{4}{|l|}{ Alemania } \\
\hline 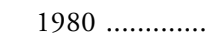 & 2,5 & 26,8 & 9,3 \\
\hline 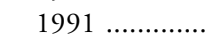 & 1,5 & 20,9 & 7,4 \\
\hline \multicolumn{4}{|l|}{ Grecia } \\
\hline 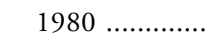 & 0,4 & 30,3 & 1,4 \\
\hline $1981 \ldots \ldots \ldots \ldots$ & 0,3 & 26,3 & 1,0 \\
\hline \multicolumn{4}{|l|}{ España } \\
\hline 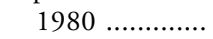 & 0,5 & 34,4 & 1,4 \\
\hline 1991 ......................... & 0,1 & 27,8 & 0,4 \\
\hline \multicolumn{4}{|l|}{ Francia } \\
\hline $1980 \ldots \ldots \ldots \ldots$ & 2,6 & 30,2 & 8,5 \\
\hline $1991 \ldots \ldots \ldots . . . . .$. & 2,2 & 27,3 & 8,2 \\
\hline \multicolumn{4}{|l|}{ Irlanda } \\
\hline $1980 \ldots \ldots \ldots \ldots$ & 1,6 & 40,0 & 4,1 \\
\hline $1991 \ldots \ldots \ldots \ldots$ & 2,2 & 36,6 & 5,9 \\
\hline \multicolumn{4}{|l|}{ Italia } \\
\hline 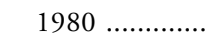 & 1,2 & 30,6 & 4,0 \\
\hline 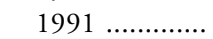 & 0,8 & 23,8 & 3,5 \\
\hline \multicolumn{4}{|l|}{ Luxemburgo } \\
\hline 1980 .................... & 2,2 & 26,7 & 8,3 \\
\hline 1991 ................... & 2,5 & 22,9 & 11,0 \\
\hline \multicolumn{4}{|l|}{ Países Bajos } \\
\hline 1980 & 2,6 & 31,3 & 8,2 \\
\hline 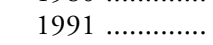 & 1,7 & 25,0 & 6,8 \\
\hline \multicolumn{4}{|l|}{ Portugal } \\
\hline $1980 \ldots \ldots \ldots$ & 0,9 & 36,9 & 2,4 \\
\hline $1991 \ldots \ldots \ldots \ldots$ & 1,0 & 29,3 & 3,4 \\
\hline \multicolumn{4}{|l|}{ Reino Unido } \\
\hline $1980 \ldots \ldots \ldots \ldots$ & 2,4 & 29,4 & 8,0 \\
\hline 1991 ............... & 2,3 & 25,9 & 8,8 \\
\hline
\end{tabular}

Fuente: Comisión de las Comunidades Europeas, "La protection sociale en Europe», Bruselas, 1993, en Revista del Instituto de Estudios Económicos, 1 y 2, 1994. 
Medido en términos por habitante, la prestación familiar directa media varía sustancialmente de un país a otro, desde un máximo del 12,4 por 100 del PIB en Dinamarca, en 1991, hasta un mínimo de 0,4 por 100 en España. Este abanico se ha ampliado durante la década de los ochenta, aumentando, en consecuencia, la disparidad en la intensidad de la protección, pues a comienzos de la década este abanico abarcaba desde un 10 por 100 en Bélgica a un 1,4 por 100 en España y Grecia. Mientras en los países que aumentó el gasto total en protección aumentó también su intensidad, en los que disminuyó también disminuyó la intensidad, salvo en el caso del Reino Unido, donde al tiempo que disminuía la proporción del gasto total aumentaba ligeramente la intensidad. Por tanto, aunque en los países tradicionalmente más generosos, como Francia y Bélgica, haya disminuido la intensidad de sus prestaciones, no puede deducirse una pauta clara de evolución en el sentido, por ejemplo, que son los países con un Estado de bienestar menos desarrollado los que han optado por sacrificar esta rama de la protección social o, viceversa, que son los países con un mayor Estado de bienestar o con mayores prestaciones familiares los que hayan limitado su compromiso con la compensación pública de las cargas familiares.

Para medir el alcance real de la protección social a la familia en la renta disponible de las familias es preciso incluir, como hemos indicado, el tratamiento fiscal dado a las cargas familiares. Dado que el tratamiento fiscal de la renta está fuertemente personalizado, no existen datos homogéneos y es preciso acudir a la elaboración de tipos de situaciones familiares para poder proceder a un análisis más detallado y poder realizar comparaciones. Una aproximación compartiva con otros países de la OCDE puede lograrse a través de OCDE, The Tax/Benefit Position of Production Workers, París, varios años. A partir de los datos proporcionados por esta publicación puede verse que la protección social integral a la familia en España es de las más bajas (véase tabla 2). El total de prestaciones familiares que percibe una familia obrera con sólo una fuente de ingresos y en cuantía igual a la media de los salarios del sector industrial y dos hijos a cargo representa únicamente entre un 5,6 y un 6,6 por 100 de sus ingresos netos anuales durante la década de los ochenta. Dado que, además, las prestaciones fiscales son en el caso español deducciones de la cuota, esto es, iguales para todos los niveles de renta, a mayor nivel de renta, menor es la incidencia de la protección. La incidencia de estas prestaciones en el nivel de vida de las familias es, por tanto, realmente mínima incluso para las familias obreras, por lo que el coste de las cargas familiares en España puede decirse está, como señalábamos anteriormente, prácticamente privatizado.

Comparado con la renta disponible de un soltero con igual nivel de ingresos, el incremento de la renta disponible derivado de la protección a la familia es realmente mínimo y uno de los más bajos de la OCDE: solamente Turquía, Grecia y Nueva Zelanda tienen un nivel inferior. En la tabla 2 hemos recogido el aumento de renta disponible después de impuestos y transferencias familiares de una familia obrera con ingresos medios (salario medio del sector industrial), 


\section{TABLA 2}

Aumento de la renta disponible neta (a) de una familia obrera con ingresos medios (b) y compuesta por cónyuge y dos hijos a cargo respecto a un trabajador soltero con iguales ingresos, medido como porcentaje del salario bruto (c)

\begin{tabular}{|c|c|c|c|c|c|c|c|}
\hline \multirow[b]{2}{*}{ Paises } & \multicolumn{7}{|c|}{ Años } \\
\hline & 1979 & 1981 & 1984 & 1987 & 1988 & 1989 & 1991 \\
\hline Bélgica .............. & 20,3 & 19,7 & 22,3 & 19,9 & 21,5 & 25,6 & 24,6 \\
\hline Dinamarca ......... & 9,8 & 9,1 & 10,7 & 12,5 & 13,9 & 14,2 & 14,4 \\
\hline Francia ............... & 13,5 & 13,9 & 15,2 & 14,2 & 14,2 & 14,0 & 14,0 \\
\hline Alemania ............ & 11,7 & 12,8 & 11,8 & 14,5 & 13,7 & 13,5 & 14,2 \\
\hline Grecia ............... & 19,3 & 19,2 & 18,9 & 1,7 & 2,5 & 2,1 & \\
\hline Irlanda .................. & 14,7 & 13,2 & 13,7 & 13,6 & 12,4 & 11,8 & 11,7 \\
\hline España ............... & 5,5 & 5,9 & 5,1 & 4,9 & 5,7 & 5,6 & 5,1 \\
\hline \multicolumn{8}{|l|}{ Italia .................. } \\
\hline \multicolumn{8}{|l|}{ Luxemburgo ..... } \\
\hline \multicolumn{8}{|l|}{ Países Bajos ...... } \\
\hline \multicolumn{8}{|l|}{ Portugal ............. } \\
\hline \multicolumn{8}{|l|}{ Reino Unido ..... } \\
\hline Suecia .............. & 10,6 & 10,2 & 8,7 & 11,4 & 10,6 & 9,5 & 11,0 \\
\hline
\end{tabular}

(a) La remuneración neta corresponde a las ganancias brutas menos el Impuesto sobre la Renta y las cotizaciones sociales más las transferencias sociales. El tipo impositivo sobre la renta utilizado para este cálculo no tiene en cuenta los efectos de las deducciones no estandarizadas.

(b) Los ingresos medios corresponden a la media de los salarios de los trabajadores del sector manufacturero.

(c) Ello quiere decir, por ejemplo, que un obrero belga con esas cargas familiares en 1990 disponía de un 24,5 por 100 más de su salario bruto que uno soltero. Sus rentas disponibles netas eran 90,5 y 90 por 100 de su salario bruto, respectivamente.

Fuente: Elaboración propia a partir de OCDE, The Tax/Benefit Position of Production Workers, París, varios años.

un solo salario, esposa y dos hijos a cargo respecto a un soltero con igual nivel de ingresos. En España, en 1990, la familia obrera disponía sólo de un 5,5 por 100 más de su salario bruto que un obrero soltero, mientras que en Bélgica era un 24,5 por 100 más y en Francia un 14,4 por 100 más. Ahora bien, también hay que destacar que esta escasa diferencia en la renta disponible neta entre familias y solteros deriva, sobre todo, de la sustancialmente menor presión fiscal a la que se ven sometidos los solteros frente a los casados, pues el porcentaje del salario neto con respecto al salario bruto (antes de impuestos y de transferencias familiares) de la familia obrera tipo, si bien no es de los más altos, sí se encuentra dentro de la banda superior: en 1990 era el 88,6 por 100 (un soltero disponía del 83,1 por 100), siendo, por ejemplo, en Bélgica el 90,5 por 100 (frente al 65 por 100), en Dinamarca el 67,5 por 100 (frente al 53,5 por 100), en Francia 
el 89,3 por 100 (frente al 74,9 por 100), en Alemania el 78,7 por 100 (frente al 65 por 100) y en Suecia el 75,4 por 100 (frente al 65,5 por 100$)^{15}$.

Un análisis complementario de esta perspectiva lo proporcionan Bradshaw y colaboradores ${ }^{16}$, quienes basándose en estos mismos datos añaden una valoración estándar sobre costes sanitarios y educativos y proceden a analizar la protección social a distintos tipos de familias en catorce países industriales avanzados. Cuando las comparaciones se refieren a unidades monetarias, los autores han procedido a su homogeneización a través de su traducción a paridades de poder de compra con arreglo a las equivalencias establecidas por Eurostat, para neutralizar así los efectos del distinto poder adquisitivo y niveles de ingresos entre los distintos países. En el gráfico 1 puede comprobarse el incremento de renta en función del número de hijos de una familia respecto a una pareja sin

\section{GRAFICO 1}

Incremento de la renta disponible de una familia con dos hijos en edad escolar según los ingresos (0,5 veces el salario medio de un trabajador, salario medio, 1,5 veces el salario medio) respecto a una pareja sin hijos. En porcentajes

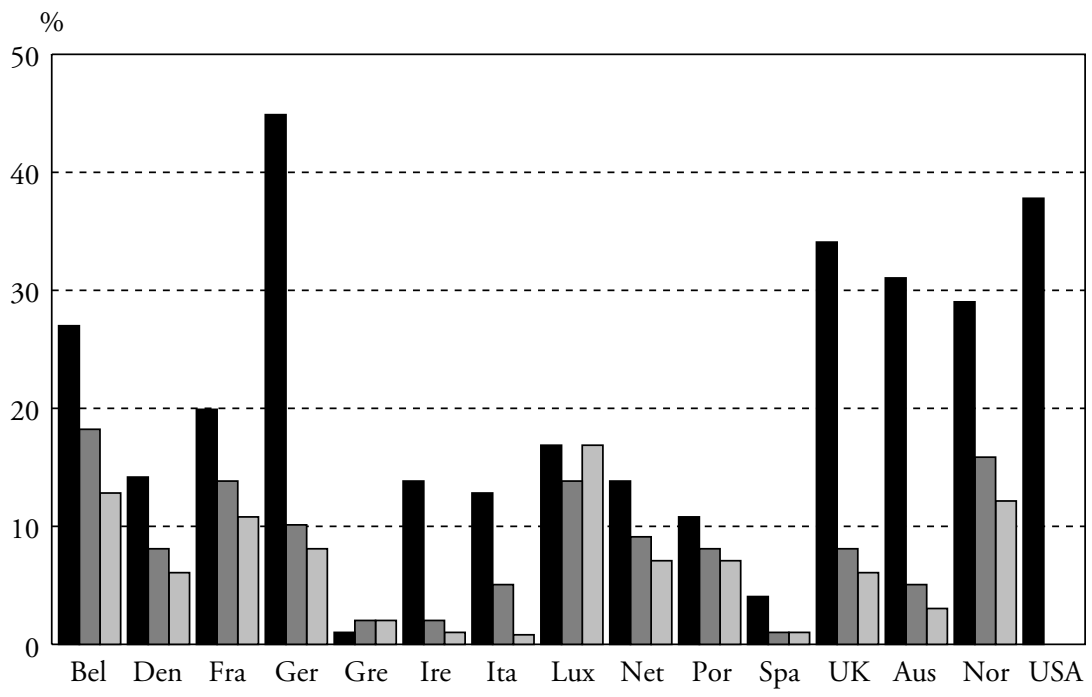

Fuente: BradshaW et al., op. cit., p. 261.

15 Para más detalles, véase OCDE, The Tax/Benefit Position of Production Workers, París, 1991 , p. 53.

16 Cf. J. Bradshaw, J. Ditch, H. Homes y P. Whiteford (1983), «A comparative study of child support in finfteen countries", en Journal of European Social Policy, 3 (4), 255-271. 
hijos con unos ingresos de 1,5 veces el salario medio. De la lectura de dicho gráfico puede deducirse que la tenencia de un solo hijo no altera sustancialmente la renta disponible de las familias acomodadas en la gran mayoría de los países. No puede afirmarse lo mismo, por el contrario, de las familias con tres o cuatro hijos: en Bélgica, Francia, Luxemburgo, Países Bajos y Noruega, la intensidad de la protección aumenta considerablemente para estas familias. Desgraciadamente, esta publicación no proporciona datos de estas mismas características para las familias con mayores ingresos, pues en general las transferencias en este caso suelen ser mayores, de suerte que en algunos países, como Francia, a mayor renta y mayor número de hijos, mayor compensación pública de cargas familiares existe. En cualquier caso, conviene retener que en un número importante de países las familias numerosas con ingresos relativamente elevados gozan de una protección importante, siendo la opción que existe en España relativamente singular (sólo Irlanda e Italia presentan unos niveles de protección casi igual de bajos).

En determinado número de países, la protección a la familia depende no sólo del número de hijos, sino también de la edad de éstos. En el gráfico 2 se recoge el incremento de renta disponible respecto a una pareja sin hijos en el

\section{GRAFICO 2}

Incremento de la renta disponible familiar según número de hijos sobre una pareja sin hijos, supuesto unos ingresos de 1,5 veces el salario medio de un trabajador. En libras y paridades de poder de compra

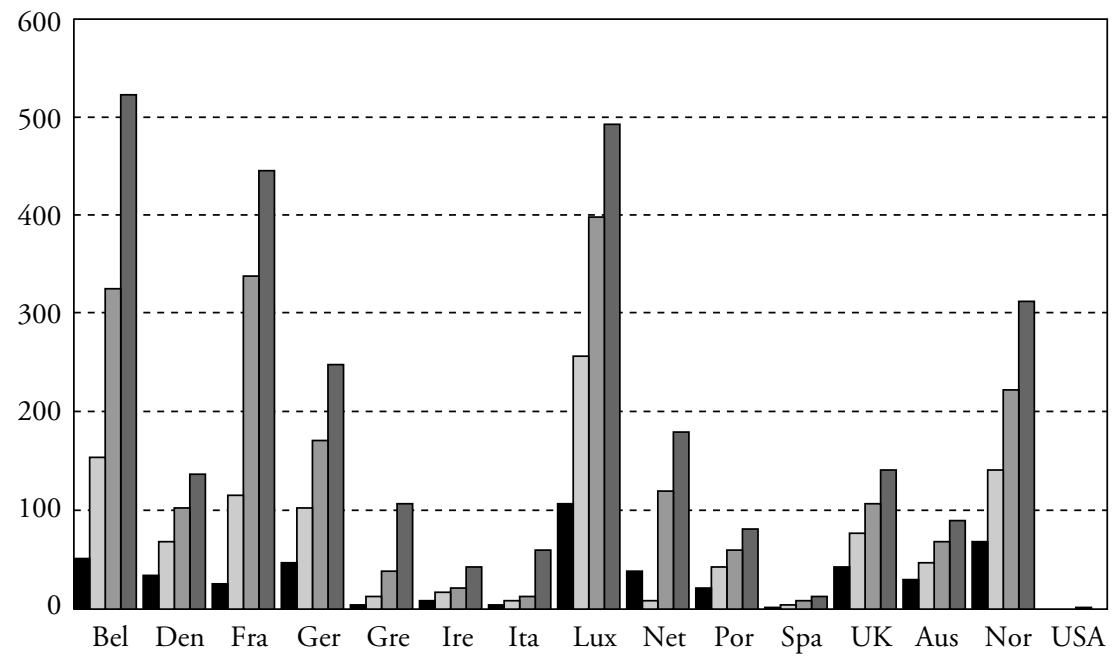

Fuente: BradshaW et al., op. cit., p. 262. 
caso de unos ingresos familiares del 50 por 100 del salario medio. En estas circunstancias, que en general son las que son acreedoras de mayor grado de protección, las opciones de los países son muy diversas. Así, mientras en Dinamarca, Francia, Noruega y, en menor medida, Irlanda se reconoce un mayor grado de protección a las familias con hijos preescolares, en Alemania, Reino Unido, Australia y Estados Unidos la compensación pública de cargas familiares es mayor cuando los hijos son más mayores, especialmente en el primer caso. En España (como en Grecia), por el contrario, la renta disponible disminuye incluso, consecuencia, probablemente, de los criterios de cálculo de la cesta de servicios públicos concedidos, pues las prestaciones económicas aplicables en este caso (prestación por hijo a cargo de la Seguridad Social) no varían con la edad y se reconocen, además, a partir del primer hijo (3.000 ptas. mensuales).

Si se prescinde del número y edad de los hijos y se centra la atención en el nivel de renta de las familias, suponiendo una familia tipo con dos hijos en edad escolar a cargo, se puede analizar la sensibilidad del sistema de protección social a las familias a la presencia de cargas familiares para distintos estratos sociales. Los resultados se encuentran resumidos en el gráfico 3, a partir del cual se pueden sacar importantes conclusiones.

\section{GRAFICO 3}

Incremento de la renta disponible de una familia con un hijo según su edad (de tres años, de siete años y de catorce años) sobre una pareja sin hijos, supuesto unos ingresos de 0,5 veces el salario medio de un trabajador. En libras y paridades de poder de compra

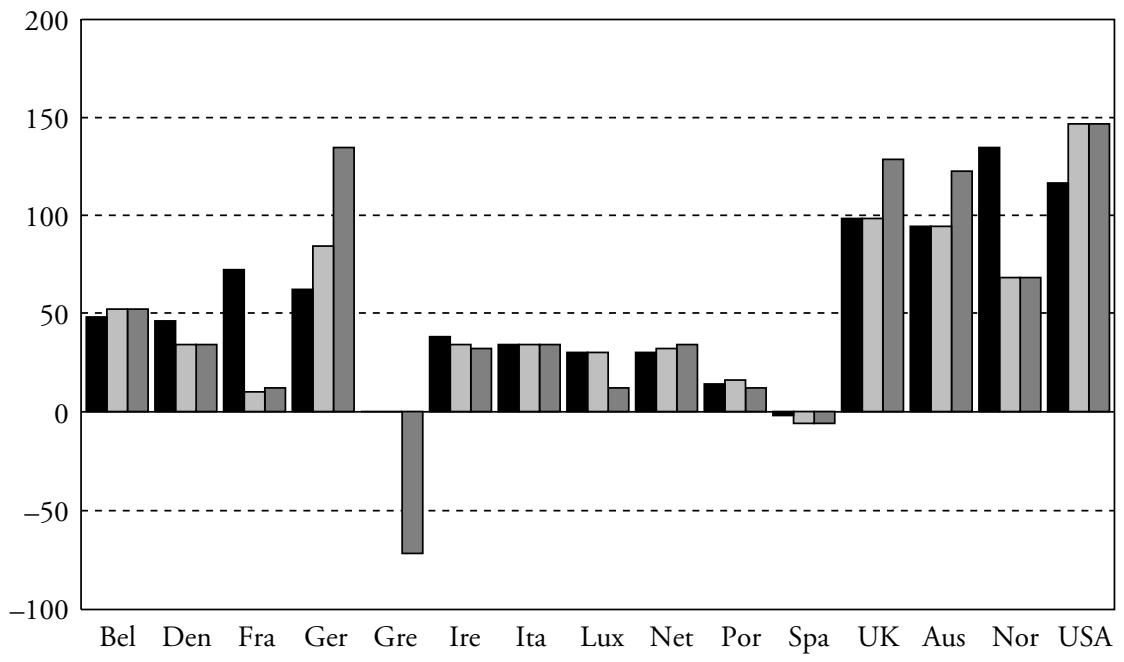

Fuente: BradshaW et al., op. cit., p. 263. 
En primer lugar, casi todos los países considerados (a excepción de Grecia y de Luxemburgo) destinan una mayor proporción de recursos a las familias con menores ingresos. El incremento de renta disponible respecto a una pareja sin hijos varía, no obstante, considerablemente de un país a otro. Así, mientras en Bélgica, Alemania, Reino Unido, Australia e incluso Estados Unidos disponen de mecanismos que permiten incrementar la renta disponible por encima de un 25 por 100 para estos colectivos, en el resto de los países la ayuda es más limitada, especialmente en el caso español, que, junto con Grecia, es el país que menor protección proporciona a las familias con menores recursos. En segundo lugar, la compensación pública de cargas familiares no se limita en la mayoría de los países a las familias con menores ingresos, si bien éste sí es el caso de Estados Unidos, Irlanda, Grecia, España y, en menor medida, Italia. Por último, las familias más acomodadas (1,5 veces el salario medio, en este caso), aunque menos protegidas que las familias con ingresos medios, también ven reconocidas las funciones sociales que cumplen asumiendo cargas familiares en la mayoría de los países. Esto es tanto más cierto, como se ha visto en el gráfico 1, cuando estas familias tienen, además, un mayor tamaño (tres o más hijos).

A partir de todos estos datos puede comprobarse que la compensación pública de cargas familiares en España es muy baja y que, por tanto, el coste de la asunción de cargas familiares está, como indicábamos en el anterior epígrafe, privatizado. La justificación parcial de esta opción con el argumento de la necesidad de concentrar los recursos disponibles para proteger más a las familias con menores ingresos se revela falaz, pues, como se acaba de ver, siendo cierto que la protección a las familias con menores ingresos es mayor que la que disponen las familias de mayores niveles de renta, esta protección es muy exigua, tanto comparativamente como si se compara respecto al coste de crianza de los hijos. Esta privatización de los costes de crianza de los hijos lleva a que hoy, como antes, las familias con mayor número de hijos se encuentren entre los colectivos sociales más desfavorecidos y con mayor riesgo de pobreza.

En efecto, una aproximación a las situaciones de necesidad y niveles de vida de los distintos colectivos sociales puede obtenerse a partir de la Encuesta de Presupuestos Familiares ${ }^{17}$. En la tabla 3 se recoge el gasto medio por hogar en 1990 para los distintos tipos de hogares según la clasificación del Censo de población. En dicha tabla puede observarse que aunque los hogares con niños son los que mayor nivel de gasto por hogar registran, medido en términos por persona, el gasto medio de los hogares con niños es inferior a la media, sobre todo entre las familias monoparentales y las familias numerosas, que son de hecho las que menor nivel de gasto por persona presentan de todos los tipos de hogar considerados.

${ }_{17}$ Para un análisis más pormenorizado y referido a la vejez, véase L. PÉrEz OrTIZ (1995), Vejez y sociedad. Fundamentos económicos de la construcción social de la vejez, tesis doctoral, Universidad Autónoma de Madrid. 
TABLA 3

Gasto anual de los hogares, por tipo de hogar. España, 1990-1991

\begin{tabular}{|c|c|c|c|c|c|c|c|c|c|c|c|c|c|c|}
\hline \multirow[b]{3}{*}{ Tipo de hogar } & \multirow{2}{*}{\multicolumn{2}{|c|}{ Gasto total }} & \multirow{2}{*}{\multicolumn{2}{|c|}{ Hogares }} & \multirow{2}{*}{\multicolumn{2}{|c|}{$\begin{array}{l}\text { Tamaño medio } \\
\text { de los hogares }\end{array}$}} & \multicolumn{6}{|c|}{ Gasto medio } & \multirow{2}{*}{\multicolumn{2}{|c|}{ Población }} \\
\hline & & & & & & & \multicolumn{2}{|c|}{ Por hogar } & \multicolumn{2}{|c|}{ Por persona } & \multicolumn{2}{|c|}{$\begin{array}{l}\text { Por unidad } \\
\text { de consumo }\end{array}$} & & \\
\hline & $\begin{array}{l}\text { Millones } \\
\text { de ptas. }\end{array}$ & $\%$ & Número & $\%$ & $\begin{array}{l}\text { Perso- } \\
\text { nas }\end{array}$ & $\begin{array}{l}\text { Unidades } \\
\text { de consumo }\end{array}$ & $\begin{array}{l}\text { Gasto } \\
\text { (ptas.) }\end{array}$ & Indice & $\begin{array}{l}\text { Gasto } \\
\text { (ptas.) }\end{array}$ & Indice & $\begin{array}{l}\text { Gasto } \\
\text { (ptas.) }\end{array}$ & Indice & Habitantes & $\%$ \\
\hline Total & $24.198 .200,1$ & 100,0 & 11.299 .850 & 100,0 & 3,4 & 2,6 & 2.141 .462 & 100,0 & 628.623 & 100,0 & 835.637 & 100,0 & 38.493 .979 & 100,0 \\
\hline $\begin{array}{l}\text { Un adulto de } 65 \text { o más } \\
\text { años, sin niños .......... } \\
\text { Un adulto con menos de }\end{array}$ & $488.436,9$ & 2,0 & 720.149 & 6,4 & 1,0 & 1,0 & 678.245 & 31,7 & 678.245 & 107,9 & 678.245 & 81,2 & 720.149 & 1,9 \\
\hline $\begin{array}{l}65 \text { años, sin niños ..... } \\
\text { Un adulto con uno o más }\end{array}$ & $488.331,0$ & 2,0 & 408.968 & 3,6 & 1,0 & 1,0 & 1.194 .057 & 55,8 & 1.194 .057 & 189,9 & 1.194 .057 & 142,9 & 408.968 & 1,1 \\
\hline 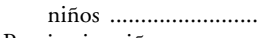 & $178.062,6$ & 0,7 & 118.815 & 1,1 & 2,9 & 2,1 & 1.498 .651 & 70,0 & 519.950 & 82,7 & 721.271 & 86,3 & 342.461 & 0,9 \\
\hline $\begin{array}{r}\text { Pareja sin niños con s.p. } \\
\text { de } 65 \text { o más años ...... } \\
\text { Pareja sin niños con s.p. }\end{array}$ & $1.249 .782,7$ & 5,2 & 1.072 .420 & 9,5 & 2,0 & 1,7 & 1.165 .385 & 54,4 & 582.693 & 92,7 & 685.521 & 82,0 & 2.144 .840 & 5,6 \\
\hline menor de 65 años ...... & $1.533 .265,1$ & 6,3 & 845.781 & 7,5 & 2,0 & 1,7 & 1.812 .839 & 84,7 & 906.419 & 144,2 & 1.066 .376 & 127,6 & 1.691 .562 & 4,4 \\
\hline Pareja con un niño ............ & $2.181 .694,1$ & 9,0 & 969.761 & 8,6 & 3,0 & 2,2 & 2.249 .723 & 105,1 & 749.908 & 119,3 & 1.006 .239 & 120,4 & 2.909 .284 & 7,6 \\
\hline Pareja con dos niños ......... & $3.516 .203,2$ & 14,5 & 1.443 .508 & 12,8 & 4,0 & 2,8 & 2.435 .874 & 113,7 & 608.968 & 96,9 & 880.196 & 105,3 & 5.774 .031 & 15,0 \\
\hline $\begin{array}{l}\text { Pareja con tres o más niños. } \\
\text { Otros hogares con dos }\end{array}$ & $1.599 .754,5$ & 6,6 & 656.764 & 5,8 & 5,3 & 3,5 & 2.435 .812 & 113,7 & 458.375 & 72,9 & 692.597 & 82,9 & 3.490 .058 & 9,1 \\
\hline $\begin{array}{l}\text { adultos, sin niños } \ldots . . . \\
\text { Otros hogares con dos }\end{array}$ & $767.097,0$ & 3,2 & 542.186 & 4,8 & 2,0 & 1,7 & 1.414 .822 & 66,1 & 707.411 & 112,5 & 832.248 & 99,6 & 1.084 .373 & 2,8 \\
\hline adultos, con niños .... & $194.611,6$ & 0,8 & 96.438 & 0,9 & 3,4 & 2,6 & 2.018 .005 & 94,2 & 587.804 & 93,5 & 789.536 & 94,5 & 331.083 & 0,9 \\
\hline Tres adultos, sin niños ..... & $2.698 .814,2$ & 11,2 & 1.281 .452 & 11,3 & 3,0 & 2,4 & 2.106 .060 & 98,3 & 702.133 & 111,7 & 877.525 & 105,0 & 3.843 .735 & 10,0 \\
\hline $\begin{array}{l}\text { Tres adultos, con niños .... } \\
\text { Cuatro o más adultos, sin }\end{array}$ & $2.726 .857,5$ & 11,3 & 1.055 .928 & 9,3 & 4,7 & 3,4 & 2.582 .427 & 120,6 & 551.812 & 87,8 & 761.153 & 91,1 & 4.941 .644 & 12,8 \\
\hline $\begin{array}{l}\text { niños ......................... } \\
\text { Cuatro o más adultos, con }\end{array}$ & $3.498 .869,2$ & 14,5 & 1.126 .238 & 10,0 & 4,4 & 3,4 & 3.106 .688 & 145,1 & 703.477 & 111,9 & 916.172 & 109,6 & 4.973 .676 & 12,9 \\
\hline $\begin{array}{l}\text { niños ........................ } \\
\text { Otros hogares encabeza- }\end{array}$ & $3.076 .420,6$ & 12,7 & 961.443 & 8,5 & 6,1 & 4,4 & 3.199 .796 & 149,4 & 526.954 & 83,8 & 731.981 & 87,6 & 5.838 .116 & 15,2 \\
\hline dos por ancianos ........ & $1.961 .681,4$ & 8,1 & 1.037 .926 & 9,2 & 3,3 & 2,6 & 1.890 .002 & 88,3 & 566.662 & 90,1 & 726.106 & 86,9 & 3.461 .818 & 9,0 \\
\hline
\end{tabular}

Fuente: L. Pérez Ortiz (1995), Vejez y Sociedad. Fundamentos económicos de la construcción social de la vejez, tesis doctoral, Universidad Autónoma de Madrid, p. 455. 
Ahora bien, la convivencia de varios miembros dentro de un mismo hogar disminuye la necesidad de determinados consumos individuales, lo que hace que los indicadores simples por persona no sean representativos en este caso; es lo que se conoce con el nombre de economías de escala. Para recoger los efectos de las economías de escala en la familia a efectos de medición del gasto existen distintas escalas de ponderación, la más aplicada de las cuales es la escala de Oxford, que pondera el consumo del cónyuge con un valor 0,7 y el de cada uno de los hijos con un valor 0,5 . Los efectos de las economías de escala medidos de acuerdo con esta escala están recogidos en el indicador de gasto por unidad de consumo. Utilizando este indicador puede volverse a constatar que las familias numerosas, al igual que las familias monoparentales, son, junto con los hogares encabezados por personas mayores, los que menor nivel de gasto relativo presentan. Dado que el gasto de las familias con menor número de hijos es mayor y que en la fase del ciclo familiar en la que se encuentran las familias numerosas y monoparentales no puede suponerse que tengan menores necesidades de consumo (como podría argumentarse, por ejemplo, en el caso de la tercera edad), es preciso concluir que la privatización de los costes de crianza de los hijos ha afectado de manera muy negativa a estos dos tipos de familias.

En efecto, estos dos tipos de familias, detrás de los hogares formados por personas mayores (especialmente si éstos tienen hijos a cargo), son los que mayor riesgo de pobreza tienen. De hecho, como puede comprobarse en la tabla 4, son estos tipos de hogares los que en mayor proporción se encuentran por debajo del umbral de la pobreza. Si se fija el umbral de pobreza en el 40 por 100 del gasto medio equivalente o por unidad de consumo (esto es, tomando en consideración las economías de escala), un umbral ciertamente muy bajo, podemos comprobar que las familias numerosas (sobre todo cuando está compuesta por hijos menores de edad) y las familias monoparentales están sobrerrepresentadas dentro del conjunto de hogares por debajo del umbral de pobreza.

Así, las parejas con tres o más hijos representan un 5,8 por 100 del total de hogares, mientras que dentro del conjunto de los hogares por debajo del umbral de la pobreza representan un 6,3 por 100 . Expresado en otros términos, mientras que la media de hogares por debajo del umbral de la pobreza es del 11,3 por 100 del total de hogares, en el caso de las familias numerosas éste se eleva a un 12,2 por 100 , porcentaje que se duplica (23 por 100) si el umbral se fija en el 50 por 100 (que es el convencionalmente utilizado). Las familias monoparentales son pocas, pues representan un 1,1 por 100 del total de hogares, pero casi una de cada cinco de este tipo de familias (19 por 100) se encuentra por debajo del umbral de la pobreza, porcentaje que se eleva a un 26,5 por 100 si éste se fija en el límite del 50 por 100 del gasto medio equivalente. Las familias con hijos pequeños y cuyo sustentador principal es mayor de sesenta y cinco años también presentan elevado riesgo de pobreza, pues la proporción de este tipo de familias por debajo del umbral de pobreza es inclu- 


\section{TABLA 4}

Pobreza: tasas especificas (TEP), distribución de la pobreza (D) según tres umbrales de gasto (40, 50 y 60 por 100 del gasto medio equivalente) y según clasificación subjetiva de los hogares, segun tipo de hogar. España, 1990-1991

\begin{tabular}{|c|c|c|c|c|c|c|c|c|c|c|c|c|c|c|c|}
\hline \multirow[b]{2}{*}{ Tipo de hogar } & \multirow{2}{*}{$\begin{array}{l}\text { Gasto medio } \\
\text { equivalente }\end{array}$} & \multicolumn{2}{|c|}{ Hogares } & \multicolumn{3}{|c|}{ Linea del 40 por 100} & \multicolumn{3}{|c|}{ Linea del 50 por 100} & \multicolumn{3}{|c|}{ Linea del 60 por 100} & \multicolumn{3}{|c|}{$\begin{array}{c}\text { Clasificación subjetiva } \\
\text { de pobreza }\end{array}$} \\
\hline & & Número & $\%$ & TEP & Hogares & $D$ & TEP & Hogares & $D$ & TEP & Hogares & $D$ & TEP & Hogares & $D$ \\
\hline 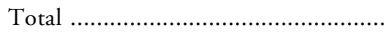 & 852.640 & 11.299 .851 & 100,0 & 11,3 & 1.276 .883 & 100,0 & 19,7 & 2.226 .071 & 100,0 & 29,0 & 3.276 .957 & 100,0 & 3,9 & 440.694 & 100,0 \\
\hline $\begin{array}{l}\text { Un adulto de } 65 \text { o más años, sin } \\
\text { niños }\end{array}$ & 678.245 & 720.149 & 6,4 & 28,3 & 203.802 & 16,0 & 40,9 & 294.541 & 13,2 & 51,5 & 370.877 & 11,3 & 6,6 & 47.530 & 10,8 \\
\hline Un adulto con menos de 65 años, sin & & & & & & & & & & & & & & & \\
\hline 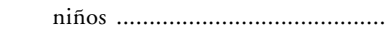 & 1.194 .057 & 408.968 & 3,6 & 10,8 & 44.169 & 3,5 & 17,3 & 70.751 & 3,2 & 24,2 & 98.970 & 3,0 & 9,0 & 36.807 & 8,4 \\
\hline Un adulto con uno o más niños ......... & 758.435 & 118.815 & 1,1 & 18,8 & 22.337 & 1,8 & 26,5 & 31.486 & 1,4 & 35,8 & 42.536 & 1,3 & 3,9 & 4.634 & 1,1 \\
\hline $\begin{array}{l}\text { Pareja sin niños con s.p. de } 65 \text { o más } \\
\text { años }\end{array}$ & 685.521 & 1.072 .420 & 9,5 & 20,6 & 220.919 & 17,3 & 32,8 & 351.754 & 15,8 & 45,2 & 484.734 & 14,8 & 4,3 & 46.114 & 10,5 \\
\hline $\begin{array}{l}\text { Pareja sin niños con s.p. menor de } 65 \\
\text { años }\end{array}$ & 1.066 .376 & 845.781 & 7,5 & 8,2 & 69.354 & 5,4 & 13,8 & 116.718 & 5,2 & 19,8 & 167.465 & 5,1 & 3,2 & 27.065 & 6,1 \\
\hline Pareja con un niño ............................. & 1.007 .962 & 969.761 & 8,6 & 4,6 & 44.609 & 3,5 & 9,4 & 91.158 & 4,1 & 16,2 & 157.101 & 4,8 & 2,0 & 19.395 & 4,4 \\
\hline Pareja con dos niños & 880.935 & 1.443 .508 & 12,8 & 6,0 & 86.610 & 6,8 & 13,2 & 190.543 & 8,6 & 22,3 & 321.902 & 9,8 & 1,5 & 21.653 & 4,9 \\
\hline Pareja con tres o más niños ................ & 698.140 & 656.764 & 5,8 & 12,2 & 80.125 & 6,3 & 22,7 & 149.085 & 6,7 & 37,2 & 244.316 & 7,5 & 6,2 & 40.719 & 9,2 \\
\hline $\begin{array}{l}\text { Otros hogares con dos adultos, sin } \\
\quad \text { niños }\end{array}$ & 832.248 & 542.186 & 4,8 & 16,1 & 87.292 & 6,8 & 25,2 & 136.631 & 6,1 & 34,8 & 188.681 & 5,8 & 6,8 & 36.869 & 8,4 \\
\hline $\begin{array}{l}\text { Otros hogares con dos adultos, con } \\
\text { niños }\end{array}$ & 799.044 & 96.438 & 0,9 & 12,2 & 11.765 & 0,9 & 22,0 & 21.216 & 1,0 & 32,4 & 31.246 & 1,0 & 6,2 & 5.979 & 1,4 \\
\hline Tres adultos, sin niños .......................... & 877.525 & 1.281 .452 & 11,3 & 10,1 & 129.427 & 10,1 & 17,9 & 229.380 & 10,3 & 26,9 & 344.711 & 10,5 & 3,2 & 41.006 & 9,3 \\
\hline Tres adultos, con niños ........................ & 775.871 & 1.055 .928 & 9,3 & 9,9 & 104.537 & 8,2 & 18,5 & 195.347 & 8,8 & 28,4 & 299.884 & 9,2 & 3,2 & 33.790 & 7,7 \\
\hline Cuatro o más adultos, sin niños ......... & 919.868 & 1.126 .238 & 10,0 & 7,3 & 82.215 & 6,4 & 12,8 & 144.158 & 6,5 & 20,4 & 299.753 & 7,0 & 3,0 & 33.787 & 7,7 \\
\hline Cuatro o más adultos, con niños ........ & 743.729 & 961.443 & 8,5 & 10,1 & 97.106 & 7,6 & 21,0 & 201.903 & 9,1 & 31,1 & 299,009 & 9,1 & 5,0 & 48.072 & 10,9 \\
\hline
\end{tabular}

Fuente: L. Pérez Ortiz (1995), Vejez y Sociedad. Fundamentos económicos de la construcción social de la vejez, tesis doctoral, Universidad Autónoma de Madrid, p. 463. 
so mayor que en los casos anteriores (21 por 100). Las familias compuestas por una pareja con uno o dos hijos menores, por el contrario, son el tipo de hogar con menor proporción de hogares por debajo del umbral de la pobreza. En conclusión, determinadas circunstancias familiares elevan el riesgo de pobreza y, por tanto, impiden la garantía de un mínimo existencial a todo menor.

\section{LA NECESIDAD DE UNA REORIENTACION DE LA POLITICA FAMI- LIAR EN ESPAÑA}

La escasa protección social a las familias con menores niveles de ingresos, la privatización del coste de crianza de los hijos, junto con el elevado riesgo de pobreza de las familias con mayor número de hijos, monoparentales o encabezadas por mayores, hablan en favor de la necesidad de una reorientación de la política familiar practicada hasta el momento. Pero, junto a estos factores, existen otras razones que cabe aducir en favor de la necesidad de una reorientación de la política familiar y que derivan de la profunda transformación que se está produciendo en los distintos subsistemas sociales y que afectan directamente a las pautas de vida familiar.

En este sentido, hay que señalar en primer término la creciente incorporación de las mujeres al mercado de trabajo, que, a diferencia del pasado, no se limita ya a los años previos a la formación de una familia. Las mujeres españolas de hoy desean compatibilizar sus aspiraciones familiares con sus aspiraciones profesionales y, además, no de forma secuencial, sino simultáneamente, porque, como es bien sabido, las posibilidades de reincorporación al mercado de trabajo tras una ruptura prolongada de la biografía laboral son limitadas. Estas aspiraciones plantean un importante reto a la política familiar y, de hecho, ha pasado a constituir, como hemos indicado, uno de los ejes fundamentales de las distintas políticas familiares nacionales.

Por otra parte, la evolución de los valores y comportamientos sociales ha hecho que la tradicional combinación sexualidad legítima-matrimonio-procreación dentro de la institución familiar se haya debilitado. De una forma cada vez más generalizada, la opción por la procreación está a disposición de las parejas, porque culturalmente la planificación familiar se ha convertido en un imperativo y porque las posibilidades de llevarla a cabo con éxito son muy elevadas. Tanto es así que se ha producido un acelerado proceso de reducción del tamaño de las familias europeas: la familia numerosa es cada vez más exótica; las familias con tres hijos han pasado ya a considerarse numerosas, cuando en otro tiempo eran el modelo ideal de tamaño familiar, y han crecido las parejas sin hijos o con únicamente un hijo. En términos demográficos, como es sabido, estos cambios se traducen en el hecho de que ya no está garantizado el nivel de reposición de la población, y en España, de continuar las pautas de fecundidad de las actuales generaciones en período reproductivo, tampoco. 
Los cambios en los valores y proyectos de vida también se han traducido en una redefinición de la solidaridad familiar entre las generaciones. Cada vez impera más el modelo de relación entre la generación mayor y la de sus hijos, que podríamos denominar de «intimidad a distancia», en virtud del cual se mantienen relaciones fluidas e intensas pero con separación de residencia; de ahí el importante crecimiento que, año a año, se registra en el número de hogares unipersonales. Esta redefinición de la solidaridad entre las generaciones tiene también sus consecuencias en la asunción por parte de las familias de la función de protección social, en el sentido de una creciente menor disposición a asumirlas. Esta tendencia hace necesario un reconocimiento por parte de los poderes públicos de la importante función que muchas familias, o, más propiamente, muchas mujeres, asumen más o menos libremente.

Otro cambio importante en la dinámica familiar que plantea un importante reto a la política familiar es la creciente importancia de las familias monoparentales debidas a la separación o al divorcio. Este fenómeno en España es limitado comparativamente con otros países, pero su importancia es creciente ${ }^{18}$ y ello afecta a los actuales mecanismos disponibles para proteger socialmente a este tipo de familias. Las tradicionales pensiones de viudedad y de orfandad, además de estar sujetas a una legislación anacrónica ${ }^{19}$, no están destinadas a proteger socialmente a este nuevo tipo de monoparentalidad. El riesgo de pobreza es, como se ha visto, elevado y resulta dudoso que los actuales mecanismos (salarios de integración y reforzamiento de la persecución penal de falta de pago de la pensión de alimentos) sean suficientes.

Todos estos cambios en dirección hacia una pluralización de las formas de vida familiares y de las solidaridades familiares, unidos al proceso de reestructuración de los sistemas de bienestar social, en el sentido de una redefinición entre las fronteras o competencias en la satisfacción de las necesidades individuales y sociales entre Mercado-Estado-Familia, o, más en general, tercer sector, todos estos cambios hacen necesario un replanteamiento de la política familiar practicada en España.

18 Así, la explotación estadística de la EPA para el Ministerio de Asuntos Sociales evidencia que la proporción de hogares monoparentales (con hijos menores de dieciocho años a cargo) encabezados por mujer y derivados de la viudedad ha pasado de representar el 47 por 100 en 1988 al 39 por 100 en 1993, mientras que los encabezados por mujeres separadas o divorciadas han pasado de representar el 40 al 46 por 100.

${ }_{19} \mathrm{La}$ actual regulación de las pensiones de muerte y supervivencia es anacrónica porque no se ha ajustado a la evolución de la realidad familiar española. Así, la limitación de su reforma a reconocer derechos de pensión también a los varones, sobre la base del principio de no discriminación, ha acentuado las situaciones contradictorias de sobreprotección, por un lado, y subprotección, por otro. Así, el cónyuge superviviente de un matrimonio con dos perceptores de renta puede compatibilizar trabajo y percepción de la pensión, y ello independientemente de la presencia de cargas familiares, mientras que una «viuda» de una pareja cohabitante sólo tiene derecho a pensiones de orfandad y éstas, además, cesan en cualquier caso cuando el beneficiario cumple dieciocho años, a pesar de que la edad de emancipación de los jóvenes se retrasa cada vez más; tampoco existe mecanismo alguno para proteger casos en los que los hijos son menores, la renta de sustitución es baja y las posibilidades de empleo son muy limitadas. 
Desde nuestro punto de vista, el objetivo de esta nueva política familiar sería crear un entorno social más favorable para que las familias pudieran asumir libremente, pero con menores costes personales, sobre todo para la mujer, opciones familiares que cumplen importantes funciones sociales, así como contribuir y reconocer el cumplimiento de dichas funciones sociales. Esto es, se trataría de establecer los siguientes objetivos:

1) Crear un entorno social más favorable para que las parejas puedan optar libremente en favor de la procreación. La creación de este entorno más favorable supone, en primer término, facilitar la compatibilización de maternidad y trabajo extradoméstico para aquellas parejas donde ambos cónyuges no quieren o no pueden renunciar a su incorporación al mercado de trabajo. Pero dado que muchas mujeres optan o se ven forzadas a asumir de forma exclusiva la resolución de tareas domésticas y familiares, una política de rentas más sensible a este tipo de familias, sobre todo para las familias con mayor riesgo de pobreza. Desde esta perspectiva sería necesaria, como puede deducirse a partir del análisis realizado en el epígrafe anterior, una protección social más efectiva de las familias numerosas, monoparentales y encabezadas por personas mayores de sesenta y cinco años. En este sentido es preciso destacar que la reciente modificación de la Ley de familias numerosas, así como la actual definición de las prestaciones por hijo a cargo de la Seguridad Social, son manifiestamente inadecuadas para lograr estos objetivos.

2) Apoyar y reforzar la función socializadora de las familias a través de distintas medidas políticas, tales como promoción de centros de asesoramiento familiar o fomento de la igualdad de oportunidades para todos los menores.

3) Apoyar y reforzar la función de protección social que asumen determinadas familias (atención y cuidado de ancianos e incapacitados), tanto mediante servicios sociales específicos como económicos.

No creemos que esta nueva orientación deba perseguir objetivos natalistas. La política familiar ha estado frecuentemente vinculada a la política demográfica y, más concretamente, al fomento de la natalidad. Dados los valores actualmente vigentes, una política de este tipo no tendría una amplia acogida y, además, la eficacia de las políticas familiares para promover la natalidad es muy limitada. La reciente historia en algunos países del Este, que acometieron importantes intervenciones en este sentido, permite evidenciar que estas políticas pueden ayudar a mantener una mayor fecundidad, aunque sus efectos tienden a diluirse con el tiempo. Según algunos estudios, el margen de acción posible de una política de apoyo a la natalidad es relativamente reducido, cifrándose entre un 0,2 y un 0,4 hijos por mujer en términos de descendencia final ${ }^{20}$. Por ello, la nueva orientación de la política familiar

${ }^{20}$ Calot, citado por L. Roussel, «Fecundidad y familia», Conferencia Europea sobre Población, Estrasburgo, 1992; reproducido por Fundación Encuentro, Servicio de Documentos, 144, p. 84 . 
debería dirigirse más decididamente a la dimensión compensatoria propia de la política social.

Una política familiar que aspire a ser eficaz tiene forzosamente que adaptarse a la realidad cultural sobre la que quiere incidir; por ello, la nueva orientación de la política familiar tendría que ser respetuosa con las opciones individuales y, por tanto, tendría que partir del reconocimiento del proceso de pluralización de las formas de vida familiar y de pluralización de las solidaridades familiares, renunciando a proteger únicamente un determinado tipo de familia, algo que los Planes de apoyo a las familias de las CC.AA. han asumido. En este sentido, no debería protegerse la institución matrimonial como tal, sino la asunción de cargas familiares en razón de la función social que con ello cumplen determinadas personas o parejas. Por ello, uno de los principios fundamentales de intervención debería ser el principio de pluralidad o neutralidad frente al vínculo matrimonial.

Otro de los principios sobre los que debería basarse la nueva política familiar es el principio de universalidad. Las familias que han optado por asumir cargas familiares cumplen, como se ha indicado, importantes funciones sociales, ya sean de socialización o de protección social, al margen del carácter expresivo que tiene para los implicados. La asunción de cargas familiares, particularmente en una sociedad en la que culturalmente ya no está fijada la obligatoriedad social de dicha asunción, tiene costes personales y económicos para quienes las asumen (menor renta disponible por persona, mayores dificultades laborales, etc.). Por ello y porque los beneficios sociales en términos de bienestar social, pero también de reducción de coste económico para el Estado de bienestar, que ello comporta son elevados, no resulta justificada la privatización casi total de los costes de esta asunción de cargas familiares. Es necesario, por tanto, un mayor grado de compensación pública de cargas familiares.

Este principio de universalidad no ha de entenderse como incompatible con la consideración de un igualmente necesario principio de igualdad de oportunidades, en el sentido de una acumulación de instrumentos de protección para determinadas familias en situaciones de riesgo o con menores ingresos. Ha de ser un objetivo prioritario de toda política familiar garantizar al menos un nivel mínimo de satisfacción de las necesidades básicas de todos los menores, que permita un adecuado desarrollo psicosocial. Puede discutirse cuál es el mínimo a garantizar y bajo qué condiciones, pero lo que resulta imprescindible es que se despierte una sensibilidad en este sentido que lleve a una amplia discusión y a arbitrar medidas más efectivas en dicha dirección.

Por último, aunque con ello no se agotan todos los principios de actuación, se hace necesario enfatizar la necesidad de un principio de complementariedad. La creación de un entorno social más favorable a la asunción de cargas familiares es una tarea en la que tienen que participar todos los agentes sociales; por ello se hace necesaria una toma de conciencia colectiva en dicha dirección. A título de ejemplo, puede citarse la tendencia en EE.UU. a que las empresas creen mecanismos de apoyo a sus empleados con cargas familiares a 
fin de evitar el absentismo laboral y la menor dedicación para conseguir una mayor productividad ${ }^{21}$.

Una política familiar explícita no puede ser un conjunto de medidas o instrumentos aislados. Se hace necesaria, máxime en un ámbito de intervención en el que confluyen multitud de políticas sectoriales como es el de la familia, una definición de objetivos y fines a lograr, plasmados en un plan, y en el que se integren distintas políticas sectoriales y que sea periódicamente evaluado. Se hace necesaria, en fin, la creación de un órgano de representación de intereses en relación a las familias que analice las políticas públicas desde la óptica de las familias. Esto es, es necesario un punto de vista o una autoevaluación similar a la que existe en el ámbito de la política de no discriminación de la mujer.

Estos son, a juicio del autor, algunos argumentos que hablan en favor de una nueva orientación de la política familiar que suponga la explicitación de la política familiar implícitamente practicada hasta ahora, a fin de facilitar la nueva redefinición en curso de las fronteras entre Mercado-Estado-Tercer sector, sin que ello suponga una simple privatización de los costes.

\section{RESUMEN}

En el presente artículo se analizan los tres grandes rasgos que caracterizan la política familiar española en la actualidad, a saber: privatización, asistencialización y fragmentación, situándolos en el marco más amplio de las grandes líneas de desarrollo de esta dimensión de la política social, sosteniéndose la tesis de que se está produciendo un cambio en la arena política en dirección hacia una mayor sensibilidad hacia la necesidad de una reorientación de la política familiar actual. Este análisis se profundiza con un estudio de la compensación pública de cargas familiares para distintos tipos de situaciones familiares desde el punto de vista, por un lado, de la comparación internacional y, por otro, del riesgo de pobreza derivado de la presencia de cargas familiares. En el último apartado se argumenta en favor de la necesidad de una reorientación de la política familiar.

\section{ABSTRACT}

This paper deals with the three main features that underpin family policy in Spain today, namely privatisation, inclusion in the sphere of welfare, and fragmentation, placing them in the broader context of the development of this component of social policy. The author contends that we are witnessing a shift in the political arena, marked by an increasing awareness of the need to redirect the current thrust of family policy. The article goes further into the study of how the state provides for dependent relatives in different family situations from the viewpoint of, on the one had, comparisons with other countries and, on the other, of the risk of skidding into poverty that results from the presence of dependent relatives. This last section vindicates the need to redirect family policy.

${ }^{21}$ NeAl et al., op. cit., pp. 191 y ss., citan, por ejemplo, medidas de facilitación de información sobre recursos comunitarios disponibles, fomento de grupos de apoyo, flexibilidad de horarios, reducción voluntaria del tiempo de trabajo, creación o concertación de servicios de respiro, etc. 